\title{
A System-on-Chip Solution for a Low Power Active Capsule Endoscope with Therapeutic Capabilities for Clip Application in the Gastrointestinal Tract
}

\author{
Oscar Alonso**, ${ }^{* \neq}$ Angel Diéguez ${ }^{*}$, Sebastian Schostek ${ }^{\dagger}$, Marc O. Schurr $^{\dagger}$ \\ *Electronics Department, University of Barcelona \\ C/ Martí i Franquès 1, Barcelona, 08028, Spain \\ ${ }^{\dagger}$ OVESCO ENDOSCOPY AG, Tuebingen, 72074, Germany
}

This paper addresses the circuit implementation challenges resulting from the integration of a therapeutic clip in a magnetically maneuverable wireless capsule intended for colonoscopy. To deal with the size constraints typical of a capsule endoscope, an Application Specific Integrated Circuit (ASIC) has been designed specifically to habilitate the release of the therapeutic clip. The ASIC is a complete System on Chip (SoC) that incorporates a circuit for the low power release of the clip, thus overcoming the limitations of the power supply system. With a size of $14 \mathrm{~mm}^{2}$, the ASIC can be incorporated in practically any capsule endoscope, consuming only an idle-state power of $1.5 \mathrm{~mW}$.

Keywords: Capsule endoscopy; therapy; endoscopy; low power; ASIC; BLDC micro-motor.

\section{Introduction}

Gastrointestinal (GI) endoscopy is a field that has progressed significantly in the last decades, both in terms of technology and clinical techniques and procedures. Being formerly used as a diagnostic tool, devices and techniques that allow first therapeutic interventions such as polypectomy were introduced. Today, endoscopists can perform procedures which before where exclusively covered by surgeons, such as hemostasis even in severe cases, resection of large areas of mucosa in a single piece, as well as closure of fistulas and perforations [1]. Novel devices and technologies continue to unfold the potential and importance of GI endoscopy for today's clinical use. The introduction of wireless capsule endoscopes around the beginning of the 21st century [2] allowed to reduce

Received 18 April 2016; Revised 22 June 2016; Accepted 12 August 2016; Published $\mathrm{xx} \mathrm{xx} \mathrm{xx}$. This paper was recommended for publication in its revised form by Editor Pietro Valdastri.

Email Address: ¥oalonso@el.ub.edu

NOTICE: Prior to using any material contained in this paper, the users are advised to consult with the individual paper author(s) regarding the material contained in this paper, including but not limited to, their specific design(s) and recommendation(s). the invasiveness of diagnostic procedures and inspect parts of the GI tract, in particular of the small bowel, that were difficult to reach with conventional flexible endoscopes before. This segment of GI endoscopy has gained importance in recent years. The technology has been proven robust and efficient.

Wireless capsule endoscopes present obvious advantages for the patient. This situation has stimulated the increase of the technical capabilities of such devices in order to extend their clinical application scenarios. At present, capsules cannot obtain biopsies, aspirate fluid or brush lesions for histology [3]. Nevertheless, when compared with flexible endoscopes, they reduce the discomfort and embarrassment of the patient, in principle allow access to the entire GI tract, reduce the length of hospital stay and procedural risk, and eliminate the need for sedation. Table 1 summarizes most of the capsule endoscopy advances done during the last years. Currently there are only a few commercial capsules [4-8]. At research level it is possible to find several capsules claiming outstanding performances in diagnosis [8-14]. There are also few devices focused on providing simple therapeutic capabilities [15-19]. 
Table 1. Capsule endoscopes.

\begin{tabular}{lll}
\hline Module & \multicolumn{1}{c}{ Innovation Done } & \multicolumn{1}{c}{ References } \\
\hline Diagnosis & CMOS image sensor & {$[6,9-11]$} \\
& 4 image sensors & {$[8]$} \\
& HD CCD sensor & {$[7]$} \\
& PH and Temp. sensors & {$[11,23]$} \\
& Fluorescence diagnosis & {$[13,14]$} \\
Therapy & Drug delivery & {$[5,18]$} \\
& Biopsy & {$[17,19]$} \\
& Clipping & {$[16]$, this work } \\
Powering & Wireless power transfer & {$[24,25]$, this work } \\
Control and & ASIC & {$[10]$} \\
processing & Micro-controller & {$[11]$} \\
& FPGA & {$[22,26]$} \\
& Image compression & {$[10,22,26]$} \\
Comms & Wireless (Mid-ISM) & {$[6,7,9-11,22]$} \\
& UWB & {$[27]$} \\
Movement & Passive & {$[6-11]$} \\
& Magnetic & {$[19]$, this work } \\
& Legged & {$[28]$} \\
& Worm-like & {$[29]$} \\
& Propellers & {$[30]$} \\
\hline
\end{tabular}

The aim of this work is to overcome some of the current limitations of capsule endoscopy by incorporating a new endoscopic over-the-scope (OTSC) system $[20,21]$ in a capsule-like device to habilitate clipping in the colon. Given the large caliber of the colon lumen, the capsule has to be stabilized externally. A capsule with the standard elements has been adapted to carry a permanent magnet. Locomotion is controlled by an extra-corporeal permanent magnet manipulated by a robotic arm.

A recently developed clipping capsule endoscope using commercial off-the-shelf electronics [22] is used as a base technology $[16,23]$. The clip release is performed using a brushless direct current (BLDC) micro-motor. The major contribution of the presented work is to integrate BLDC motor drivers and the control electronics in an Application Specific Integrated Circuit (ASIC), which highly reduces the space required by the electronics as well as the power consumption. The ASIC is a System-on-Chip that integrates a microcontroller, motor drivers, I2C controller and a low speed serial communication unit to receive commands.

In this paper, the authors describe in Sec. 2 the capsule-like device. The architecture of the System-on-Chip and its main features is described in Sec. 3. In Sec. 4, the low-power BLDC motor driver is discussed in more detail. System integration is explained in Sec. 5.

\section{Therapeutic Device}

Most of the elements of the therapeutic device are common in conventional capsules. For diagnosis in the small intestine a camera, a transceiver, LEDs, optics, a dome and a shell are used. In conventional capsule endoscopy the images are sent wirelessly by the transceiver integrated while the capsule moves by peristaltic movements. In the case of exploration of the colon, active control of the capsule position and orientation is required. In the clip deployment this is also necessary. The therapeutic device will be moved actively through the colon to the region of interest and will be used to release the OTSC clip in a secure and controlled way. The motion of the therapeutic capsule is achieved by means of an external magnetic locomotion control [23-25]. Movement is obtained by the interaction of a magnet guided by a robotic arm above the patient and a permanent magnet inside the capsule $[26,27]$. To continuously track the position and orientation of the device is possible using an inertial sensor and a special arrangement of the magnet inside the capsule as previously done in [28]. The inertial sensor data allows for a closed sensor feedback cycle that stabilizes the endoscope to perform a soft and secure movement.

The OTSC clip is placed in an applicator cap mounted on the capsule tip. Figure 1 shows an image of a therapeutic capsule endoscope that integrates the mentioned clip. The total size of the capsule-like device with the clip is $37 \mathrm{~mm} \times 13 \mathrm{~mm}$, which can be used easily in the colon. The OTSC is a device made of super-elastic Nitinol, which is biocompatible for long-term implantation. In the clinical field it is used in hemostasis $[29,30]$, closure of fistulas [31] and perforations [32]. The clip is shown in

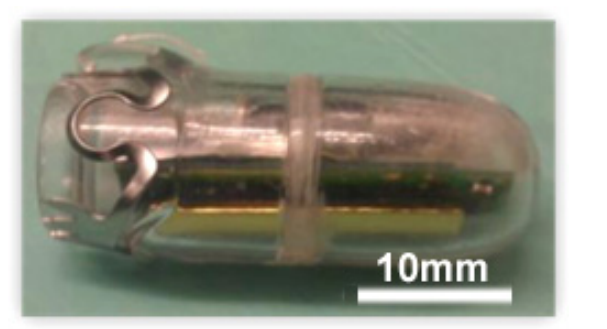

Fig. 1. Capsule-like therapeutic endoscope. The OTSC clip is at the tip of the capsule.

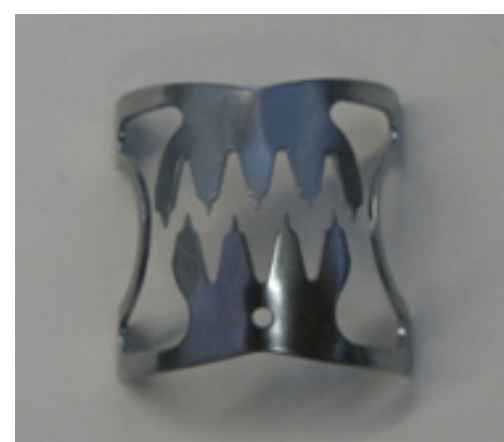

Fig. 2. OTSC clip. 
Fig. 2. Based on its unique design, the clip closes itself and firmly anchors the tissue to be compressed for hemorrhage or closure of a GI organ wall lesion. The clip is released just once. A Faulhaber BLDC motor (0515B motor with $06 \mathrm{~A}$ gear and a reduction ratio of $625: 1)$ is used to pull a biocompatible wire attached to the clip. BLDC motors can provide enough force to deploy the clip (c.a. $10 \mathrm{~N}$ ). A schema of the releasing concept is shown in Fig. 3. When the command to release the clip is received, the BLDC motor is continuously pulling the wire and winding it onto the shaft until the clip is released. The operation speed is limited by the available power. Pulling until the release of the clip avoids an unintentional release in case of power failure.

It is not possible to do the driving of a motor with the chips currently used in capsule endoscopy. Moreover, the utilization of off-the-shelf components for driving the motor is difficult because of the lack of free volume after the incorporation of the motor in the capsule. Apart from that, the therapeutic device is also constrained by the limited power. A high current is necessary to release the OTSC clip, in particular during the start-up of the BLDC motor [33]. This severely limits the integration of therapeutic units in the size of an endoscopic pill. To overcome this obstacle, an ASIC that integrates a new BLDC motor driver, designed to reduce the power consumption during the start-up of the motor, has been used. The custom Integrated Circuit (IC) also solves the problem of the reduced volume available, as it can substitute several off-the-shelf chips and passive components that would be needed to manage all the capsule functions and the release of the clip. The IC acts as a slave device, driving the BLDC motor when the activation command is received telemetrically. The ASIC is programmed from a small EEPROM memory during the power-up. In this development, an off-the-shelf microcontroller controls the inertial sensor dataflow, the ASIC and the transceiver. Orders from the external operator are also managed by the microcontroller. The architecture of the endoscope including these elements is schematically shown in Fig. 4. The capsule is powered with a 3D inductive link that can provide up to $250 \mathrm{~mW}$ in the operation conditions. Details of the 3D inductive link can be found in $[26,34]$.

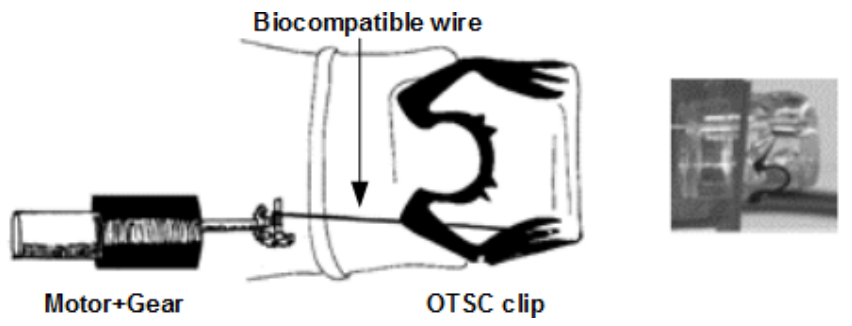

Fig. 3. Schema and detail of the release mechanism. The BLDC motor pulls a wire attached to the OTSC clip.

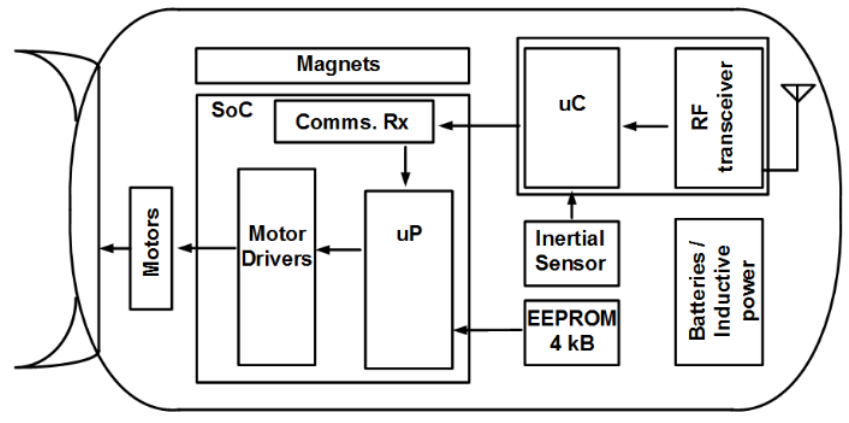

Fig. 4. Schematic of the architecture of the therapeutic capsule.

\section{System-on-Chip Architecture}

The ASIC has been fabricated in a $0.35 \mu \mathrm{m}$, high voltage technology because it offers enough power capabilities to drive the motor as well as the high density required for the integration of the digital controller and satellite functions. The ASIC can be used either in master mode to control the basic functions of a capsule plus the driving of the motor or in slave mode managed by the microcontroller in the therapeutic device.

The architecture of the ASIC is illustrated in Fig. 5. The different modules of the ASIC are indicated in the ASIC photograph of Fig. 6. An embedded 8051 microprocessor acts as the control unit (Synopsys (C) DW8051 [35]) of the IC. The inclusion of the microprocessor in the ASIC provides more flexibility to the system and facilitates the debug. The microprocessor has 256 B of internal SRAM memory. The ASIC uses $512 \mathrm{~B}$ of SRAM data memory and $4 \mathrm{kB}$ of SRAM program memory. As the memory used is volatile, each time that the ASIC is powered up, the program has to be uploaded to the memory. Since EEPROM memories have not been integrated in the ASIC, an external $4 \mathrm{kB}$ SPI EEPROM memory is used to program the IC.

To achieve the necessary low-power, a Power Management Unit (PMU) controls the clock of each block. Among other activities, the PMU is responsible for starting the system with low-power consumption. This is necessary in this autonomous device. During power-up, the Power-on-Reset signal forces the PMU to activate the Boot Loader (BL) only, which reads the external EEPROM and programs the internal memory. This process is carried out at $10 \mathrm{kHz}$ in order to have low power consumption. Once programmed, if the ASIC is in master mode, it wakes up the microprocessor. When it acts as a slave, it waits for orders via the I2C bus or through the communication module (CCU). The other blocks rest in power down mode until the PMU receives the order to wake them up.

The I2C control unit (I2CCU) is a finite state machine (FSM), which can work as a master or as a slave. External resistors have been used in open drain outputs to have I/Os 
o. Alonso et al.

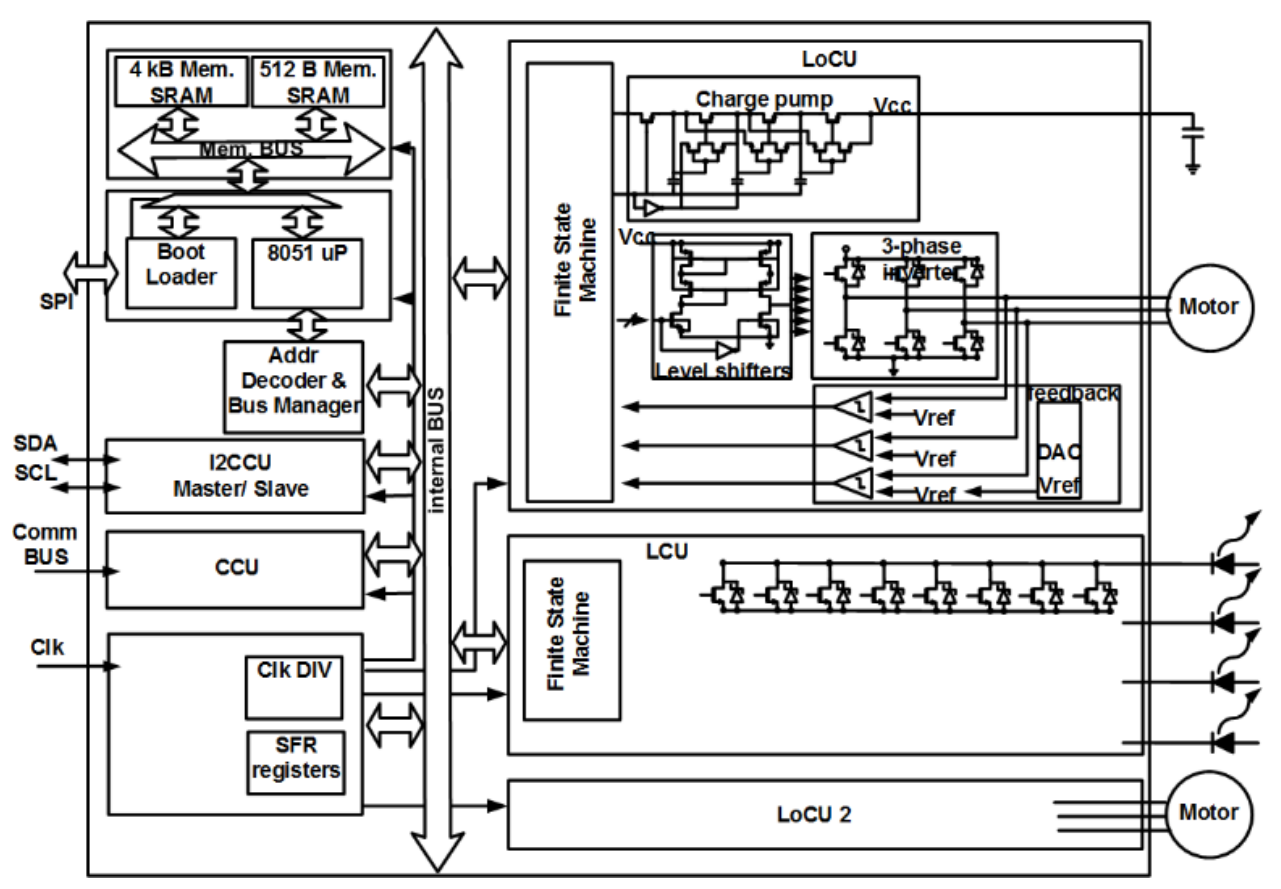

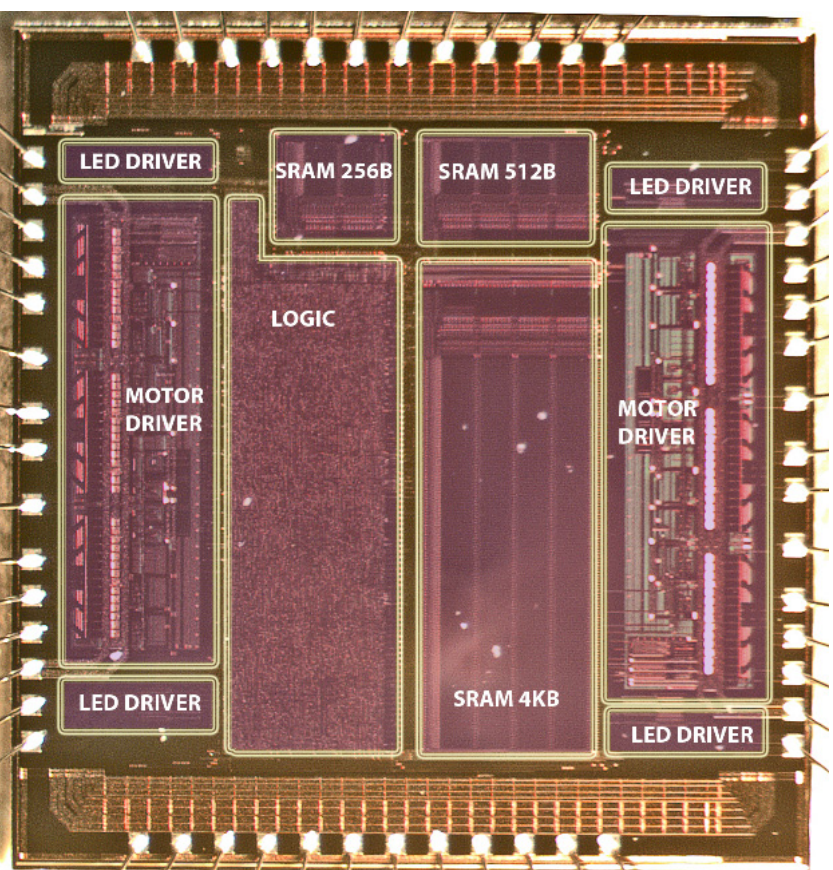

Fig. 6. Schematic of the architecture of the mixed-mode low-power IC. images to the external receiver, both controlled by the I2C control unit.

Data from the off-the-shelf microcontroller included in the therapeutic capsule is received by the CCU. The CCU is a FSM that decodes and feeds the received data to the embedded microprocessor. The data is received at $4.8 \mathrm{kbps}$ by a serial input. The CCU usually is in sleep mode. To start the receiving process, the transmitter has to send a logic one followed by the data (16 bits). Once received, the CCU generates an interruption and returns to sleep mode. The interruption is processed by the embedded microprocessor. The ASIC also includes four LED drivers (LCU) that are used to control the illumination during the navigation of the capsule. Two motor drivers (LoCU) have been included. It is possible to control up to 3 DC motors or 2 BLDC motors at the same time. Nevertheless, only one driver is necessary for each OTSC clip. The BLDC motor driver is based on a traditional 3-phase inverter structure, which is typically used for BLDC control [36-38]. Table 2 summarizes the main characteristics of the ASIC.

\section{Low-Power BLDC Micro-Motor Driver}

BLDC motors have high efficiency and reliability, are low noise, present a long lifetime and generate low electromagnetic interferences. BLDC sensor-less micro-motors are widely used in challenging areas of application such as medical devices, handling automation and precision optics. In small autonomous devices the feasibility to use 
Table 2. Summary of the main characteristics of the ASIC.

\begin{tabular}{|c|c|c|}
\hline Characteristics & Property & $\begin{array}{c}\text { External } \\
\text { Devices Needed }\end{array}$ \\
\hline Size & $3.65 \mathrm{~mm} \times 3.85 \mathrm{~mm}$ & \\
\hline Power (IDLE) & $1.5 \mathrm{~mW}$ & \\
\hline Thickness & $250 \mathrm{um}$ & \\
\hline $\begin{array}{l}\mathrm{N}^{\circ} \text { equivalent } \\
\text { gates }\end{array}$ & $20 \mathrm{k}$ & \\
\hline \multirow[t]{3}{*}{ Memories } & 1 SRAM (4 kB) & \\
\hline & 1 SRAM (512 B) & \\
\hline & 1 SRAM (256 B) & \\
\hline \multirow[t]{6}{*}{ Analog circuits } & 2 DAC (8-bits) & \\
\hline & 6 Comparators & \\
\hline & 2 3-phase inverters & \\
\hline & 2 Charge pumps & \\
\hline & 1 Power on reset & \\
\hline & 6 Level-shifters & \\
\hline \multirow[t]{5}{*}{ Modules } & LED drivers & 16 LEDs \\
\hline & BLDC driver & $36 \mathrm{nF}$ \\
\hline & & BLDC motor \\
\hline & Master/Slave I2C & $\begin{array}{l}2 \text { pull up resistor } \\
(1 \mathrm{kOhm})\end{array}$ \\
\hline & Communication unit & \\
\hline
\end{tabular}

BLDC micro-motors is conditioned by the capacity of the supplying system and the reduced available space. Nowadays, most of the solutions that integrate BLDC micro-motors rely on the reduction of the power consumption of the driver or the supply of recharges for the battery. Although these solutions extend the battery lifetime, they do not have any effects on the start-up of the motor. In a conventional start-up, the current required may be higher than that delivered by the power system. As a consequence, the electronics may fail due to the excessive current delivery and the drop of the biasing voltage. Even in the clipping application, where the clip is released only once, this limits the applicability of this type of motors. Apart from that, BLDC motor drivers must deal with the problem of the freewheeling currents, thus requiring volume to include external freewheeling diodes or implement synchronous rectification. In this work, the conventional motor driver has been modified in order to perform a low power start-up while reducing substantially freewheeling currents without using external freewheeling diodes or synchronous rectification. This methodology eliminates the need for external elements and hence reduces the volume required for the control of the motor. A driver for BLDC motors has been designed to eliminate the two above mentioned problems.

The control of the motor is usually done with a threephase inverter in a six-step commutation schema [39], where commutation is controlled by position sensors. To reduce the cost and complexity of the drive system, a sensor-less drive is preferred [40-43]. In sensor-less operation, the commutation is based on the measure of the back electromotive force (BEMF). The start-up of the motor is critical and sometimes difficult for a BLDC sensor-less system. Once the rotor is aligned, it is possible to measure the BEMF signal and perform the sensor-less control with the integrated FSM by means of Pulse Width Modulation (PWM). This control allows to regulate the power according to the motor operation [44]. The magnitude of the back-EMF is directly proportional to the motor speed. This makes it extremely difficult to measure the BEMF at low speed, since the signal-to-noise ratio is very small. To accelerate the motor, a start-up process is applied to the BLDC motor, as it is shown in Fig. 7. A practical start-up tuning procedure consists in cycling the bridge at maximum speed until the wings are tuned in a few steps (typically in 6-12 steps). During this stage, the transistors in the bridge are opened for more time than in the stationary phase to assure the movement of the rotor (see the alignment phase in Fig. 7). As a consequence of the higher torque needed during the start-up, a higher current goes from the bias to ground through the bridge transistors. The BEMF feedback stage is composed of three comparators and an R-2R digital to analog converter. Each comparator senses each motor phase. Proper BEMF reading can be achieved by skipping one electrical commutation ahead by $120^{\circ}$ and waiting for the zero crossing on the respective floating coil.

The Faulhaber micro-motors used in the wireless device require up to $100 \mathrm{~mA}$ during the start-up, which is unaffordable with the available powering system (250 mW @3.3 V are delivered by the RF inductive link). This justifies the utilization of a driver specifically designed to activate the therapeutic clip. The schematic of the driver was presented in Fig. 5. The three-phase inverter structure was designed with $5 \mathrm{~V}$ transistors and is supplied at $3.3 \mathrm{~V}$. The current that goes through each phase of the bridge is given by the MOSFET saturation current:

$$
I_{\text {Dsat }}=\frac{\mu_{n} C_{\mathrm{OX}} W_{n}}{2 L_{n}}\left(V_{\mathrm{GS} n}-V_{\mathrm{TH} n}\right)^{2},
$$

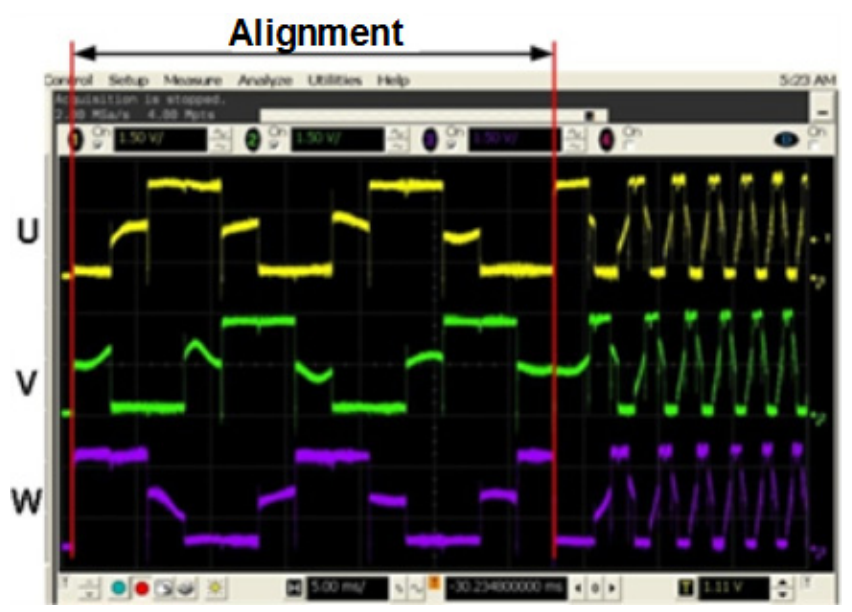

Fig. 7. Start-up of the BLDC motor using 12 steps to align the rotor. $\mathrm{U}, \mathrm{V}$ and $\mathrm{W}$ are the 3-phase bridge control signals.

\section{5-5}


where $\mu_{n}$ is the charge-carrier effective mobility, $C_{\mathrm{ox}}$ the gate oxide capacitance per unit area, $W_{n}$ the gate width, $L_{n}$ the gate length, $V_{\mathrm{GS}}$ the gate-source voltage and $V_{\mathrm{TH}}$ the threshold voltage of the $n$ MOS transistor. From (1), two methods to limit the current supplied to the motor can be inferred. It is possible to control either the supply voltage or the gate voltage of the transistors used in the driver. Previous works have been focused on the control of the supply voltage $[45,46]$. The approach followed here is based on the control of the gate-source voltage during the start-up. The advantage is that it is easily integrable in the driver without increasing the driver area, which is important in capsule endoscopy. Figure 8 shows the current flowing through one of the phases of the bridge for different transistor sizes and gate-source voltages. The phases were designed with nMOS transistors only, which are isolated in different wells to avoid latchup issues and noise affecting the rest of the ASIC. The transistor size is fixed in the ASIC by the maximum necessary current, while the driving current used, is controlled by the gate-source voltage. A Dickson type charge pump [47] and 6 level-shifters drive the transistors in the three-phase structure (Fig. 5). The charge pump can generate up to $5 \mathrm{~V}$ from a $1.8 \mathrm{~V}$ source. The output voltage of the charge pump is controlled by changing the operation frequency and the PWM signal, as usual. The level-shifters are used to adapt the controlling signals from $3.3 \mathrm{~V}$ to the new levels generated by the charge pump. During the start-up, the charge pump is programmed to the minimum output voltage $(2.5 \mathrm{~V})$. This voltage is fixed by the PWM signal and the input of the charge pump $(V$ bias $=1.8 \mathrm{~V})$. In the stationary phase, the PWM signal is adapted to increase the output voltage up to $5 \mathrm{~V}$ and the motor speed is handled by the FSM motor controller.

A comparison between the current consumption during a normal start-up and the low power start-up is

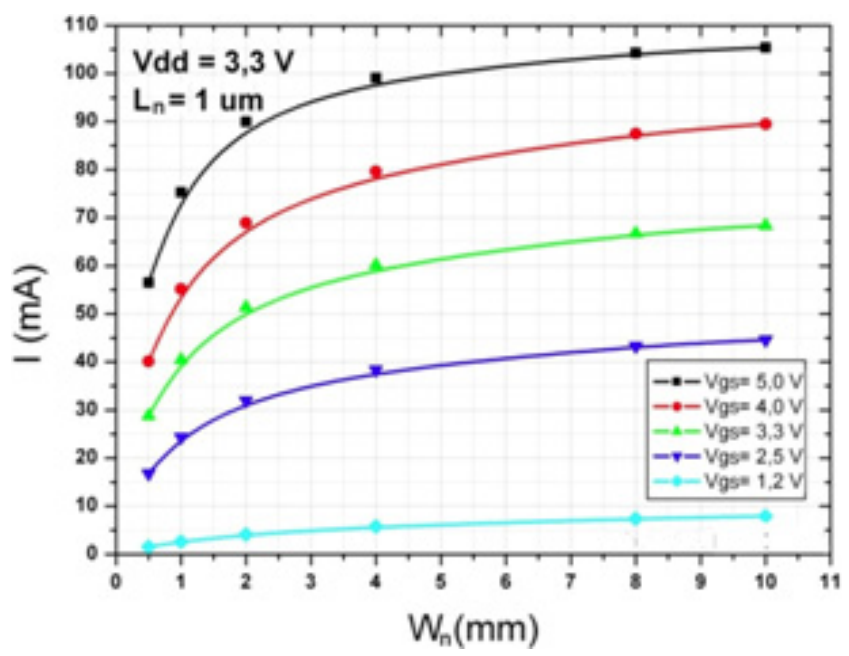

Fig. 8. Current obtained for the $n$ MOS $/ n$ MOS structure of the bridge depending on the width, $W n$, of the transistors and the voltage at the gate of a $n$ mos transistor, $V$ gs.

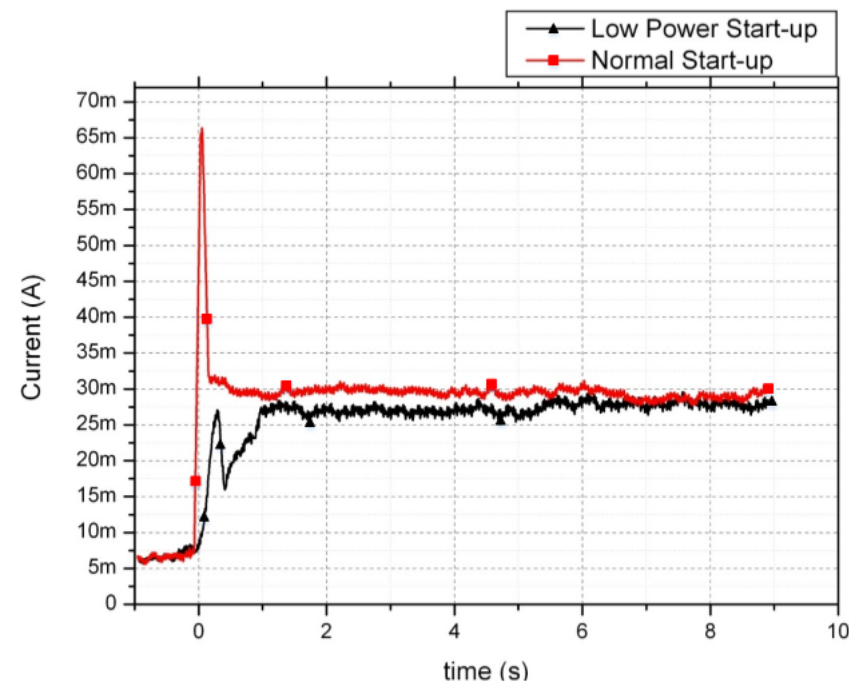

Fig. 9. Comparison between the current needed by a Namiki BLDC motor during a normal start-up (red) and a low power start-up (black) versus time.

illustrated in Fig. 9 for a Namiki BLDC motor. To demonstrate the low power operation mode of the driver, the charge pump has been programmed to generate a ramp from $2.5 \mathrm{~V}$ to $5 \mathrm{~V}$ in $1 \mathrm{~s} .1 \mathrm{~s}$ is approximately the minimum time required to have the rotor aligned with the controlling signals. The result has been compared to a normal start-up where the charge pump directly generates $5 \mathrm{~V}$. As shown in Fig. 9, the current peak of the start-up is significantly reduced from $66 \mathrm{~mA}$ to $27 \mathrm{~mA}$ by controlling the gate-source voltage during the start-up. The same procedure can be applied to other motors. The final prototype of the capsule has a Faulhaber motor. The main difference when compared with the Namiki motor is that it requires $100 \mathrm{~mA}$ during a conventional start-up. Nevertheless, the torque is higher.

The driver also deals efficiently in terms of space with the freewheeling current problem of BLDC drivers. Instead of using external freewheeling diodes or synchronous rectification, the control of the switching time of the transistors in the driver has been performed to reduce freewheeling currents. The transistors of the three-phase structure are switched on/off slowly enough to reduce the effect of the magnetic flux on the driver. As shown in Fig. 10, a switching time of $30 \mu \mathrm{s}$ almost eliminates the freewheeling current. It also induces deformed spikes in the current, but these do not alter the motor operation. In the presented driver, the slow switching time has been implemented with the proper transistor sizing of the level-shifters.

\section{System Integration}

The therapeutic device has been fully integrated to prove that a clipping mechanism can be done in a wireless 


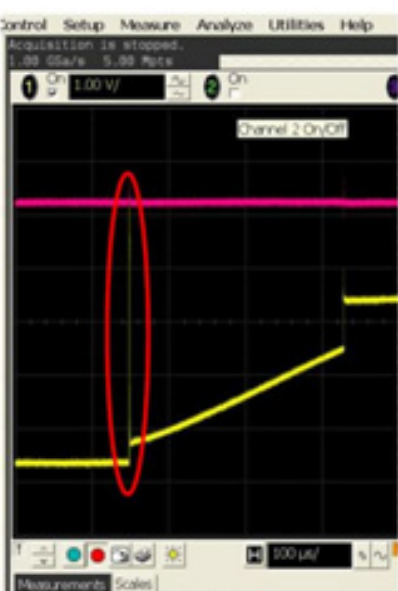

(a)

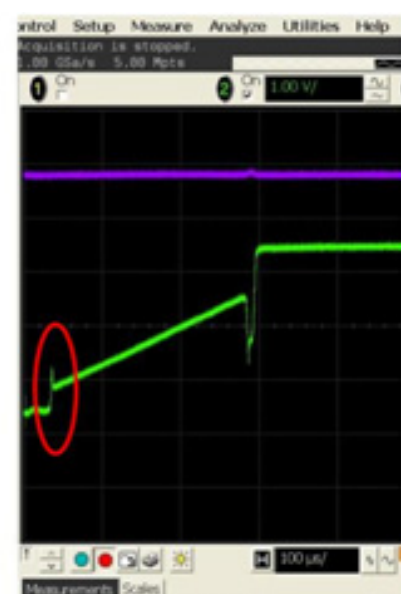

(b)
Fig. 10. Oscilloscope images of the current in a motor phase (bottom lines). (a) Driver with freewheeling currents. (b) Driver with control of the switching time and without freewheeling currents.

capsule endoscope. The therapeutic endoscope consists of a dedicated printed circuit board (PCB), a Faulhaber BLDC micro motor, the OTSC clip, a magnet used for magnetic locomotion and a 3D inductive link, all inside the endoscope shell (Fig. 1). The PCB has some accessible pins that are used to program the EEPROM memory and the microcontroller.

All the electronics needed are assembled in a single PCB (Fig. 11). It includes a CC1101 receiver, a DSC1001 oscillator and an EEPROM memory on the bottom side. The microcontroller, a level-shifter (used to adapt the $1.8 \mathrm{~V}$ signals from the microcontroller to $3.3 \mathrm{~V}$ for the ASIC), the inertial sensor, the ASIC and two LDOs used to generate $1.8 \mathrm{~V}$ and $3.3 \mathrm{~V}$ are on the top side. The size of the PCB is $33 \mathrm{~mm} \times 12 \mathrm{~mm}$, and therefore fits in the capsule. Table 3 summarizes the list of components and their power consumption. Nevertheless, it is clear that

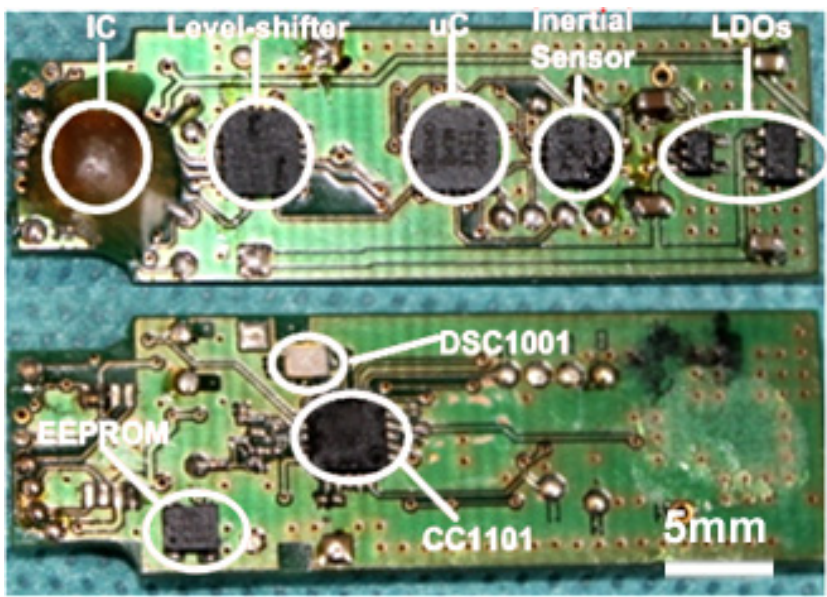

Fig. 11. Photograph of the PCB integrated in the capsule.

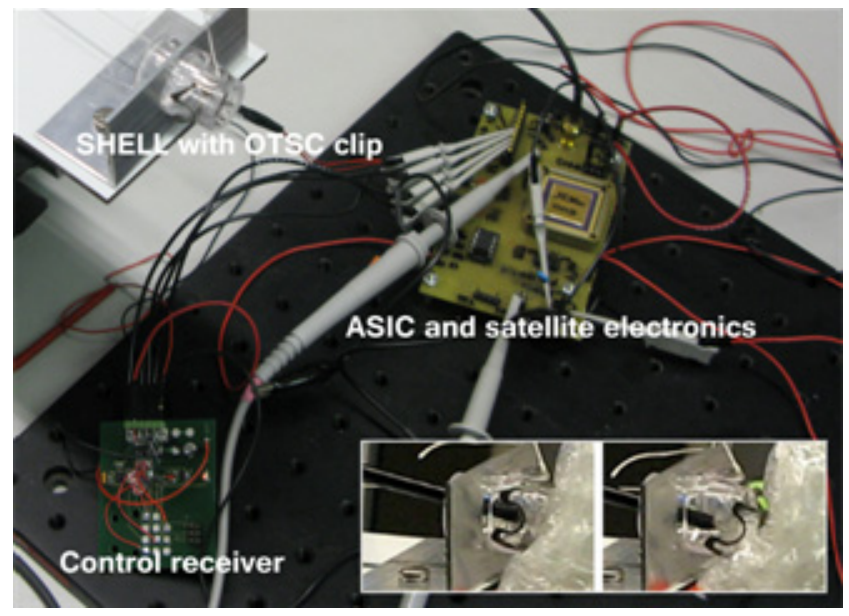

Fig. 12. Setup for the test of the clip release and release sequence.

considerable further miniaturization can be achieved by integrating most of these elements in the ASIC.

During the test, a 3D inductive link was used to power the device [34]. Although this 3D inductive link is capable to generate up to $400 \mathrm{~mW}$, in the present application it can only supply $250 \mathrm{~mW}$ since the internal magnet of the capsule modifies the magnetic field. Interferences between the inductive link and the electronics have not been observed as they work with a significantly different frequency [48].

Different tests were conducted in order to fix the conditions under which the clip is released to perform the desired action. The release of the clip is possible only if a low power start-up is used. The maximum current possible is limited to $65 \mathrm{~mA}$. With a conventional start-up it is not possible to deploy the clip because the Faulhaber BLDC motor requires nearly $100 \mathrm{~mA}$. Figure 12 shows the setup used to test the release of the clip.

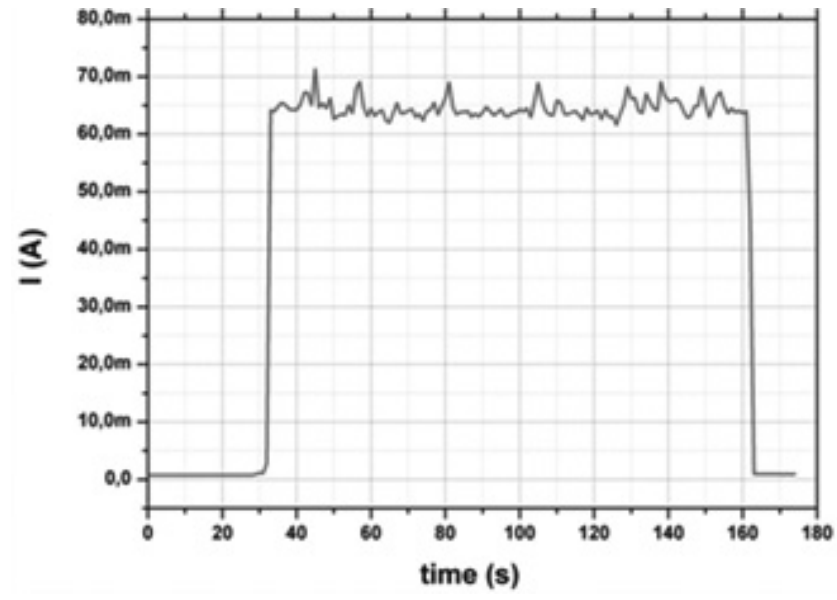

Fig. 13. Measured current in the motor during the release of the clip. 


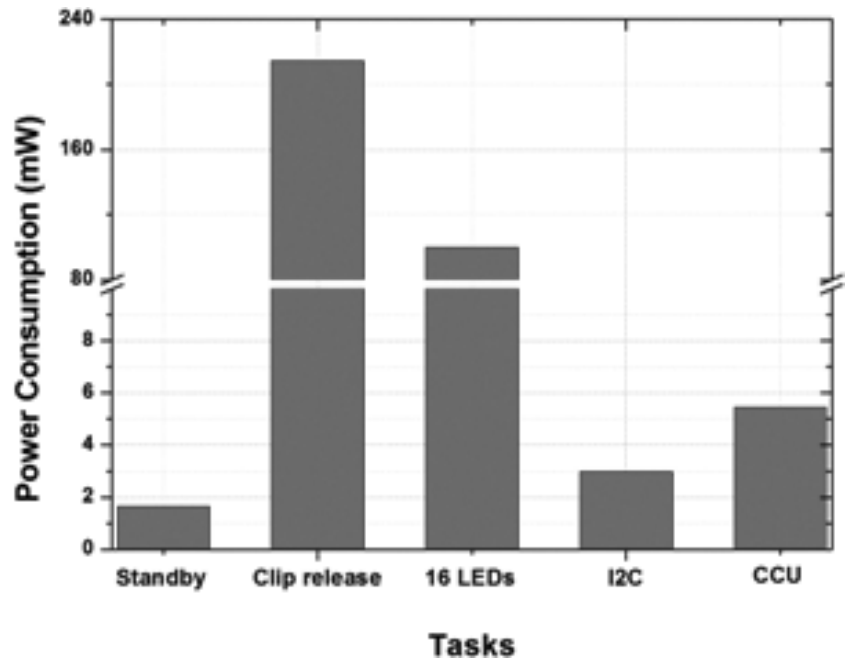

Fig. 14. Measured power consumption of the ASIC.

The release order is sent wirelessly by an external unit. A control receiver is connected to the ASIC, which is assembled in a test PCB with satellite electronics. The ASIC is powered by the output of the RF inductive link system (not shown). The ASIC drives a Faulhaber motor pulling a biocompatible wire connected to the clip, which is on a capsule shell. Figure 13 shows the current delivered to the motor during the releasing of the clip. The release process takes approximately $130 \mathrm{~s}$. In Fig. 14, the power required by the different modules of the ASIC is plotted. The stand-by power is $1.5 \mathrm{~mW}$. This low power is achieved by controlling the activity of the digital part and switching-off most of the analog modules. The driving of the motor consumes a maximum power of $215 \mathrm{~mW}$ during the release of the clip, which is performed only once. The power consumption of the digital modules always includes the power of the embedded processor. The clock of the system is $10 \mathrm{MHz}$. To limit the power consumption, dynamic frequency scaling (DFS) is used. With DFS, the total power required for operation of the digital part during the organization of the different tasks (clip release, LED activation, communications) is always below $10 \mathrm{~mW}$. This power management strategy allows

Table 3. Summary of the components included in the capsule device.

\begin{tabular}{llc}
\hline Module & \multicolumn{1}{c}{ Part Name } & Power Consumption \\
\hline EEPROM & 25LC320 & $0.5 \mathrm{~mA}$ (read) @ 1.8 V \\
& & $0.5 \mu \mathrm{A}$ (standby)@ $1.8 \mathrm{~V}$ \\
uC & Atmel ATtiny24 & $0.3 \mu \mathrm{A} @ 1.8 \mathrm{~V}$ \\
Oscilator & DSC1001 & $7.2 \mathrm{~mA} \mathrm{@} 1.8 \mathrm{~V}$ \\
Comms. & CC1101 & $15.6 \mathrm{~mA} \mathrm{@} 1.8 \mathrm{~V}$ \\
Inertial sensor & LIS3DH & $11 \mu \mathrm{A} @ 1.8 \mathrm{~V}$ \\
ASIC & & $1.5 \mathrm{~mA}$ (IDLE) @ 3.3 V \\
& & $215 \mathrm{~mA}$ (MOTOR) @ 3.3 V \\
\hline
\end{tabular}

to never exceed the total available power of $250 \mathrm{~mW}$ of the $\mathrm{RF}$ inductive link.

\section{Conclusions}

Since the apparition of the first capsule endoscope in the market, most of the developments in capsule endoscopy have been focused on improving the conventional capabilities of the state-of-the-art capsules, especially the vision, in order to extend the clinical applications of wireless capsule endoscopy. One important aspect that can be considered as a current drawback of wireless capsule endoscopy is that capsules cannot be actively maneuvered to perform any therapeutic intervention. A step forward towards capsules which are equivalent to flexible endoscopes has been done. With the prototyped ASIC, the BLDC micro-motor and the OTSC clip it is possible to approach to a GI lesion in a controlled manner to perform a therapeutic intervention. The ASIC is a complete controller of the therapeutic clip. It integrates a low-power BLDC motor driver to allow activation of the clip with current technology for micro-motors and powering at the capsule size scale. The OTSC clip, the BLDC motor, the control ASIC and the inductive power system plus some magnets needed to enable active locomotion, have been added to a capsular shape of only $37 \mathrm{~mm} \times 13 \mathrm{~mm}$. Thanks to the integration achieved the final size of this endoscope perfectly fits to the operation in the colon.

\section{Acknowledgments}

This work was supported in part by the EC project VECTOR "Versatile Endoscopic Capsule for Gastrointestinal Tumor Recognition and Therapy" coded FP6-2007IST-033970.

\section{References}

1. J. Pohl, M. Delvaux, C. Ell, G. Gay, A. May, J. Mulder, M. Pennazio, E Perez-Cuadrado, P. Vilmann and the ESGE Clinical Guidelines Committee. European Society of Gastrointestinal Endoscopy (ESGE), Guidelines: Flexible enteroscopy for diagnosis and treatment of small-bowel diseases, Endoscopy 40 (2008) 609-618.

2. G. Iddan, G. Meron, A. Glukhovsky and P. Swain, Wireless capsule endoscopy, Nature 405 (2000) 417-418.

3. P. Guobing and W. Litong, Swallowable wireless capsule endoscopy: Progress and technical challenges, Gastroenterol. Res. Pract. 2012 (2012) 1-9.

4. C. Li, B. Zhang, C. Chen and Y. Li, OMOM capsule endoscopy in diagnosis of small bowel disease, J. Zhejiang Univ. Sci. 9 (2008) 857-862.

5. Philips, Available at: http://www.research.philips.com/technologies/ipill.html [accessed on 12 April 2016]. 
6. Given Imaging, Available at: http://www.givenimaging.com/enint/Innovative-Solutions/Capsule-Endoscopy/Pillcam-SB/PatientResources/Pages/default.aspx [accessed on 12 April 2016].

7. C. Gheorghe, R. Lacob and I. Bancila, Olympus capsule endoscopy for small bowel examination, J. Gastrointestin. Liver Dis. 16(3) (2007) 309-313.

8. CapsoCam, Available at: http://www.capsovision.com/ [accessed on 12 April 2016].

9. S. Bang, J. Park, S. Jeong, H. Kim, H. Shim and T. Kim, First clinical trial of the MiRo capsule endoscope by using a novel transmission technology: Electric-field propagation, Gastrointest. Endos. 69 (2009) 253-259.

10. X. Xie, G. Li, X. Chen, X. Li and Z. Wang, A low-power digital IC design inside the wireless endoscopic capsule, J. Solid-State Circuits 41(11) (2006) 2390-2400.

11. RF Labs, Available at: http://www.rfsystemlab.com [accessed on 12 April 2016].

12. A. Lehman, M. Rentschler, S. Farritor and D. Oleynikov, The current state of miniature in vivo laparoscopic robotics, J. Robot. Surg. 1 (2007) 45-49.

13. M. Kfouri, O. Marinov, P. Quevedo, N. Faramarzpour, L. Liu, F. Qiying and M. Deen, Toward a miniaturized wireless fluorescencebased diagnostic imaging system, IEEE J. Sel. Topics Quantum Electron. 14(1) (2008) 226-234.

14. M. Al-Rawhani, J. Beeley, D. Chitnis, S. Collins and D. Cumming, Wireless capsule for autofluorescence detection, in Proc. Eurosensors XXVI (2012), pp. 48-51.

15. A. Lehman, K. Berg and J. Dumpert, Surgery with cooperative robots, Comput. Aided Surg. (2008) 95-105.

16. P. Valdastri, C. Quaglia, E. Susilo, A. Menciassi, P. Dario, C. N. Ho, G. Anhoeck and M. O. Schurr, Wireless therapeutic endoscopic capsule: in vivo experiment, Endoscopy 40(12) (2008) 979-982.

17. K. Kyoungchul, D. Jeon, S. Yim and S. Choi, A robotic biopsy device for capsule endoscopy, J. Med. Dev. 6(3) (2012) 1-9.

18. S. Woods and T. Constandinou, Wireless capsule endoscope for targeted drug delivery: Mechanics and design considerations, IEEE Trans. Biomed. Eng. 60(4) (2013) 945-953.

19. Y. Sehyuk, E. Gultepe, D. Gracias and M. Sitti, Biopsy using a magnetic capsule endoscope carrying, releasing, and retrieving untethered microgrippers, IEEE Trans. Biomed. Eng. 61(2) (2014) 513-521.

20. A. Arezzo, M. Verra, R. Reddavid, F. Cravero and M. Morino, Efficacy of the over-the-scope clip (OTSC) for treatment of colorectal postsurgical leaks and fistulas, Surg. Endoscopy 26 (2012) 33303333.

21. OVESCO, Available at: http://www.ovesco.com/[accessed on 12 April 2016].

22. P. Valdastri, C. Quaglia, A. Menciassi et al., Surgical clip releasing wireless capsule, European Patent Application 08425604.9 (2008).

23. VECTOR "Versatile Endoscopic Capsule for Gastrointestinal Tumor Recognition and Therapy", FP6 European Project (2011).

24. F. Rieber, P. Trôbner and M. O. Schurr, Capsule type endoscope including magnetic drive, EP 2347699 Patent (2010).

25. M. O. Schurr, Surgical manipulator, DE 2011052615 Patent (2011).

26. G. Ciuti, P. Valdastri, A. Menciassi and P. Dario, Robotic magnetic steering and locomotion of capsule endoscope for diagnostic and surgical endoluminal procedures, Robotica 28(2) (2010) 199-207.

27. G. Ciuti, R. Donlin, P. Valdastri, A. Arezzo, A. Menciassi, M. Morino and P. Dario, Robotic versus manual control in magnetic steering of an endoscopic capsule, Endoscopy 42 (2010) 148-152.

28. G. Ciuti, P. Valdastri, A. Menciassi and P. Dario, Robotic magnetic steering and locomotion of capsule endoscope for diagnostic and surgical endoluminal procedures, Robotica 28 (2010) 199-207.
29. K. Leung and J. Y. Lau, New endoscopic hemostasis methods, Clin Endosc. 45(3) (2012) 224-229.

30. ASGE Technology Committee, L. M. Wong Kee Song, S. Banerjee, B. A. Barth, Y. Bhat, D. Desilets, K. T. Gottlieb, J. T. Maple, P. R. Pfau, D. K. Pleskow, U. D. Siddiqui, J. L. Tokar, A. Wang and S. A. Rodríguez, Emerging technologies for endoscopic hemostasis, Gastrointest. Endosc. 75(5) (2012) 933-937.

31. R. Manta, M. Manno, H. Bertani, C. Barbera, F. Pigò, V. Mirante, E. Longinotti, G. Bassotti and R. Conigliaro, Endoscopic treatment of gastrointestinal fistulas using an over-the-scope clip (OTSC) device: Case series from a tertiary referral center, Endoscopy 43(6) (2011) 545-548.

32. R. P. Voermans, O. Le Moine, D. von Renteln, T. Ponchon, M. Giovannini, M. Bruno, B. Weusten, S. Seewald, G. Costamagna, P. Dprez and P. Fockens, Efficacy of Endoscopic closure of Acute Perforations of the Gastrointestinal Tract, Clin. Gastroenterol. Hepatol. 10 (6) (2012) 603-608

33. cap-XX, Current-limit and low-voltage lockout circuit for portable devices (2001) Available at: http://www.cap-xx.com/resource/ an1001-pdf/[accessed on 12 April 2016]

34. R. Carta, B. Lenaerts, J. Thone, G. Tortora, P. Valdastri, A. Menciassi, R. Puers and P. Dario, Wireless power supply as enabling technology towards active locomotion in capsular endoscopy, in Proc. Eurosensors XXII (2008), pp. 1369-1372.

35. Synopsys Inc., Guide to Design Ware DW8051 Macrocell Documentation (2005)

36. A. Azidehak, M. Hoshyari and M. A. Sharbafi, Design and implementation of minimal components brushless DC motor driver for mobile robots, in Proc. IEEE Int. Conf. Mechatronics (2011), pp. 642-647.

37. D. Krkljes, C. Morvai, K. Babkovi and L. Nagy, BLDC motor driver Development of control and power electronics, in Proc. Int. Conf. Microelectronics (2010), pp. 345-348.

38. W. T. Lee, H. W. Lu, Y. Z. Liao, S. T. Feng and Y. S. Hwang, Chip design of three-phase BLDC motor brake driver IC, in Proc. IEEE Conf. Electron Devices and Solid-State Circuits (2007), pp. 497-500.

39. N. Mohan, T. Undeland and W. Robbins, Power Electronics: Converters, Applications, and Design (Wiley, 2002).

40. T. Hui, K. Basu and V. Subbiah, Permanent magnet brushless motor control techniques, in Proc. National Power and Energy Conference (PECon) (2003), pp. 133-138.

41. K. Iizuka, H. Uzuhashi, M. Kano and T. Mohri, Microcomputer control for sensorless brushless motor, IEEE Trans. Ind. Appl. 4 (1985) 595-601.

42. S. Ogasawara and H. Akagi, An approach to position sensor-less drive for brushless DC motors, IEEE Trans. Ind. Appl. 5 (1991) 928-933.

43. K. Ramu, Permanent Magnet Synchronous and Brushless DC Motors (CRC Press, 2009).

44. A. Lita and M. Cheles, Microchip AN1160: Sensorless BLDC contro with back-EMF filtering using a majority function.

45. A. Bradley, J. Loprete, D. Monk, T. Simerly and J. Tolbert, System and method for soft starting a three phase motor, EP 1508195A1 Patent (2002)

46. J. Skaarup, Method for starting an electric motor and starting circuit for an electric motor, W02007134605 Patent (2007).

47. M. Ahmadi and G. Jullien, A new CMOS charge pump for low voltage applications, IEEE Int. Symp. Circuits and Systems (2005), pp. 4261-4264.

48. R. Carta, G. Tortora, J. Thoné, B. Lenaerts, P. Valdastri, A. Menciassi, P. Dario and R. Puers, Wireless powering for a self-propelled and steerable endoscopic capsule for stomach inspection, Biosens. Bioelectron. 25(4) (2009) 845-851. 
Oscar Alonso is Doctor in Engineering and Advanced Technologies (27th April 2012) by the University of Barcelona. His Ph.D. Thesis, entitled 'Enabling active locomotion and advanced features in an endoscopic capsule' and carried out under the supervision of Dr. Angel Diéguez, was qualified cum laude and was awarded with the Honors Doctorate by the Univesity of Barcelona.

Pysicist and Electronic Engineer, with nine years experience in CMOS design, FPGA operation and system integration. Expert in desing of Application Specific CMOS Integrated Circuits. In the last five years, his research has been focused in capsular endoscopy and high-sensitivity photon detectors, mainly based on Avalanche Photodiode Devices, applied to high energy particles detection, molecular fluorescence signals and in vivo imaging. $\mathrm{He}$ is co-founder of ENDOASIC Technolgy, a start-up company of the department of electronics focused on integrated imaging in endoscopic environments.

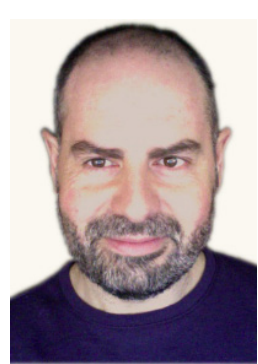

Angel Diéguez received the Ph.D. degree in Physics from the University of Barcelona (UB) Spain, 1999. Since 2001, he is an Associate Professor at the Department of Electronics of UB. His research activities have been developed mainly in the field of basic semiconductor research and microelectronic circuit design. He has participated actively in six European projects and has more than 40 papers. His main areas of interest are mixed-signal design of ICs and low-power VLSI design. Specific research topics are microrobotics, low-power smart sensor systems, radiation tolerant electronics and vision systems. During the last decade he has developed research and innovation developing ASICs and electronic systems for microrobotics applied to medical and biological sciences. He participated in the FP7 European project VECTOR, "Versatile Endoscopic Capsule for Gastrointestinal Tumor Recognition and Therapy", developing integrated circuits for capsule endoscopy. As a result of the research done he founded endoASIC Technologies in 2013, a fables company oriented to the endoscopy field. Now he is CEO of this company.

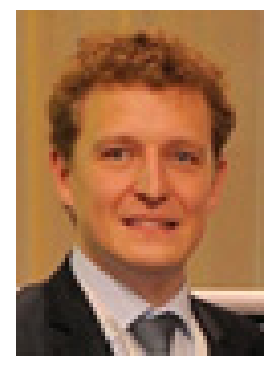

Sebastian Schostek graduated in Engineering Physics from the Munich University of Applied Sciences in 2004, and received his Ph.D. degree from the Faculty of Medicine of Eberhard Karl University Tuebingen in 2010. He worked as research fellow and Lecturer at the IHCI - Institute of Healthcare Industries, Steinbeis University Berlin, before he joined novineon Healthcare Technology Partners GmbH, Tuebingen, as Business Unit Director in the fields of technological and medical research, medical product development, contract research, and business consulting. Throughout his career, he was involved in a number of national and international research projects. His work led to numerous publications, patents, lectures and awards. In 2011, he accepted the position as Vice President of the Division Diagnostic Systems at Ovesco.

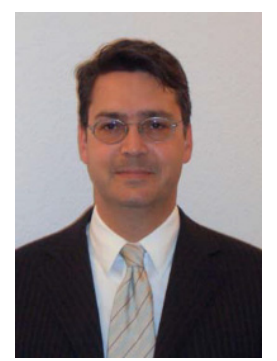

Marc 0. Schurr, MD, attended the Medical School of Eberhard-Karls University Tuebingen, Germany and took his doctoral degree in the area of medical technologies. Before founding Ovesco Endoscopy he was in charge of a research programme into advanced technology of Tuebingen University and has directed a medical technology transfer center. Besides his appointment at Ovesco Endoscopy Marc Schurr is also Managing Director of novineon $\mathrm{GmbH}$, an international CRO, consulting and venturing firm in the medical technology area. In the academic field he is Director of IHCI - Institute at Steinbeis University Berlin, where he is Professor of Experimental Medicine and Medical Technology. 